\title{
Tek Değişkenli Modellerde Uygun Test İstatistiğinin Seçilmesi İçin Web Tabanlı Bir Kılavuz
}

\author{
A Web-Based Guide in Choosing the Appropriate \\ Test Statistics for Univariate Models
}

Öz

Amaç: Araştırmacıların günümüzde istatistiksel paket program kullanma oranı çok yüksektir. Bu çalışmada tek değişkenli modellerde temel düzeydeki istatistiksel analizleri yapmak isteyen araştırmacılara uygun test istatistiğinin seçimi sırasında kılavuzluk edebilecek, mümkün olan en az karmaşıklık düzeyinde web tabanlı bir karar ağacı geliştirmek amaçlanmıştır.

Gereç ve Yöntemler. Tek değişkenli basit veya çoklu modellerin istatistiksel analizinde hangi test istatistiğinin uygun olduğunun belirlenişine yönelik bir kılavuz olarak geliştirilen karar ağacı, PHP ve JavaScript dilleri yardımıyla oluşturulmuştur. Kılavuzun kolayca kullanılabilmesi için kavramlar ve testlere ilişkin teknik bilgiler açilır pencereler içinde verilmiştir.

Bulgular. Ulaşması ve kullanması oldukça kolay olan karar ağacında araştırmacılara sorulan sorularla çalı̧manın amacı, tasarımı ve veri tipi saptanarak uygun yöntemler genelden özele doğru indirgenmekte ve araştırmacının bilgi eksikliğinden ya da yanlış yönlendirmeden kaynaklanan hata yapma olasılı̆ı azaltılmaktadır. Ayrıca, ileri istatistiksel yöntemlerin varlı̆ı ve özellikleri konusunda araştırmacılar bilgilendirilerek uzman yardımı almanın önemi de vurgulanmıştır.

Tartışma ve Sonuç: İstatistiksel değerlendirme sonucunda elde edilecek bulguların doğruluğu ve güvenilirliği açısından doğru testin seçilmesi oldukça önemlidir. En önemlisi paket program kullanabilmek ya da bir testi uygulayabilmek değil, istatistiksel analiz için doğru testi seçebilmektir. Geliştirilen karar ağacı, uzman yardımı almanın önemini vurgulamakla birlikte, temel düzeydeki istatistiksel değerlendirmeleri kendi başına yapmak isteyen araştırmacıların en azından yöntem seçimi sırasında hata yapma olasılığının azalmasına katkı sağlayacaktır.

Anahtar Sözcükler. Uygun test istatistiği seçimi; istatistiksel analiz; tek değişkenli modeller

\section{Abstract}

Aim: The rate of statistical software use among researchers today is very high. In this study we aimed to develop a web-based decision tree at the least possible confusion level that can provide guidance in choosing the appropriate test statistics for researchers who want to perform the basic statistical analyses in univariate models on their own.

Materials and Methods: The decision tree developed as a guide in determining the appropriate test statistics in the statistical analysis of simple or multiple univariate models was created by using PHP and JavaScript languages. Technical information on the concepts and tests was provided in pop-ups for the guide user's convenience.

Results: The questions posed within this decision tree that is quite easy to reach and use help reduce possible appropriate methods by fixing the research's aim, design and data type and lower the researcher's possibility to make mistakes due to lack of knowledge or misguidance. In addition, the information provided on the existence and nature of more advanced statistical methods emphasizes for the researcher the importance of consulting with an expert during the statistical analysis of a study's results.
Mehmet Ali Sungur, Handan Ankaralı, Şengül Cangür

Düzce Üniversitesi, Tıp Fakültesi, Biyoistatistik ve Tıbbi Bilișim AD, Düzce, Türkiye
Gelis Tarihi /Received : 13.07.2016 Kabul Tarihi /Accepted: 16.08.2016

DOI: 10.21673/anadoluklin.284434

Sorumlu Yazar/Corresponding Author Yrd. Doç. Dr. Mehmet Ali Sungur Düzce Üniversitesi, Tıp Fakültesi, Biyoistatistik ve Tıbbi Bilișim AD, Konuralp/Düzce, Türkiye E-mail: malisungur@yahoo.com 
Discussion and Conclusion: Choosing the right test is crucial for the accuracy and reliability of findings to be obtained from a statistical analysis. What is essential is the ability to choose the right test for statistical analysis, not the ability to perform a statistical test or use statistical software. In addition to emphasizing the importance of consulting with an expert, a decision tree as developed in this study will contribute to lowering the possibility of making mistakes of researchers who want to perform statistical analyses on their own, at least while their choice of method.

Keywords: Choosing appropriate test statistics; statistical analysis; univariate models

\section{GíRiş}

Verinin söz konusu olduğu her araştırmada bulgular ortaya çıkarılırken yapılan ilk çalışma, istatistiksel yöntemlerle verileri değerlendirme ve bunlara bir anlam kazandırma çalışmasıdır. Araştırma sonucu ise elde edilen bu bulgular ışı̆̆ında şekillenmekte, dolayısıyla bulguların doğruluğu büyük bir önem arz etmektedir. Bulguların, yani verilerin istatistiksel analizi ile elde edilen sonuçların doğruluğu ise öncelikle ve özellikle veriye ve amaca uygun test istatistiğinin kullanılmasına bağlıdır (1-3).

Günümüzde bilgisayar kullanım becerisi özellikle bilimsel araştırmacılar arasında çok yüksektir ve bunun doğal bir sonucu olarak, istatistiksel analiz paket programlarını kullanarak kendi verilerini analiz etme çabaları da oldukça fazladır. Tanımlayıcı istatistiksel hesaplama, tablo ve grafik oluşturma gibi bazı temel istatistiksel işlemlerin yanı sıra araştırmacılar, basit grup karşılaştırmaları, temel düzeyde ilişki varlığının araştırılması gibi işlemleri de kendi başlarına gerçekleştirebilmek istemektedirler. Bu konuda en büyük güçlük ise uygun test istatistiğinin seçimi sırasında yaşanmaktadır $(2,4,5)$. Test seçiminde genellikle; alan uzmanı olmayan kişiler ile görüş alış-verişi yapılarak edinilen genel kültür düzeyindeki bilgiler veya diğer akademisyenlerden alınan öneriler ışı̆̆ında, ya da o konuda en çok kullanılan yöntemleri tercih etmek suretiyle karar vermeye çalışılmaktadır. Paket program sayısının artışı ve yaygınlığı, istatistiksel yöntemlerin bilinçsiz kullanımını da beraberinde getirmekte, istatistiksel analiz için sadece paket program kullanma becerisi yeterli olmadığından araştırmacılar çok sayıdaki alternatif test arasından hangisini seçecekleri konusunda zorlanmaktadırlar (6).

$\mathrm{Bu}$ çalışmanın amacı, temel düzeydeki istatistiksel değerlendirmeleri kendi başına yapmak isteyen alan dişından araştırmacılara uygun test istatistiğinin seçimi konusunda yardımcı olacak, ulaşılması, kullanılması ve anlaşılması kolay web tabanlı bir kılavuz geliştirmektir.

\section{GEREÇ VE YÖNTEMLER}

\section{Uygun Test İstatistiğinin Seçimi}

Uygun istatistiksel test seçiminde, analiz edilecek veri ve kurulacak model hakkında karar verebilmek için ilk olarak bağımlı ve bağımsız değişkenlerin tipi, çalışmanın amacı, farklılık veya ilişkilerden hangisinin araştırıldığı, modelde yer alacak bağımlı ve bağımsız değişken sayıları ve kategorik bir değişken söz konusuysa bu değişkenin seviye sayısının bilinmesi gerekmektedir $(1,3,4,7,8)$. Oluşturulan modelde kategorik bir bağımsız değişkenin seviyeleri karşılaştırılacak ise bu seviyelerin (grupların) bağımlı veya bağımsız oluşunun da belirlenmesi gerekmektedir. Bu bilgilerden sonra, son olarak ilgili test istatistiklerinin varsayımları kontrol edilerek kullanılacak uygun test istatistiğine karar verilir. Tek değişkenli modellerde seçilebilecek test istatistiklerinin hangileri olabileceği bağımlı ve bağımsız değişkenin tipine göre aşağıda ayrı ayrı şekillerde gösterilmiştir. İlk olarak bağımlı değişken sayısal ve bağımsız değişken kategorik, yani, amaç kategorik bir bağımsız değişkenin seviyelerini karşılaştırmak olduğunda kullanılabilecek test istatistikleri verilmektedir (Şekil 1). Daha sonra hem bağımlı hem de bağımsız değişken kategorik, yani amaç kategorik bir bağımsız değişkenin seviyelerini karşılaştırmak ve/ veya iki kategorik değişken arasındaki ilişkiyi araştırmak olduğunda kullanılabilecek test istatistikleri verilmektedir (Şekil 2). Son olarak hem bağımlı değişken hem de bağımsız değişken sayısal, yani amaç iki sayısal değişken arasındaki ilişkiyi araştırmak olduğunda kullanılabilecek test istatistikleri verilmektedir (Şekil 3).

\section{Programlama Dilleri}

$\mathrm{Bu}$ çalışmada, uygun test istatistiğinin belirlenmesine kılavuzluk etmesi amacıyla PHP dili ve JavaScript kodları kullanılarak Apache sunucu üzerinde çalışan, tüm platformlar ve web tarayıcılar ile görüntülenebilen web tabanlı bir karar ağacı oluşturulmuştur. 


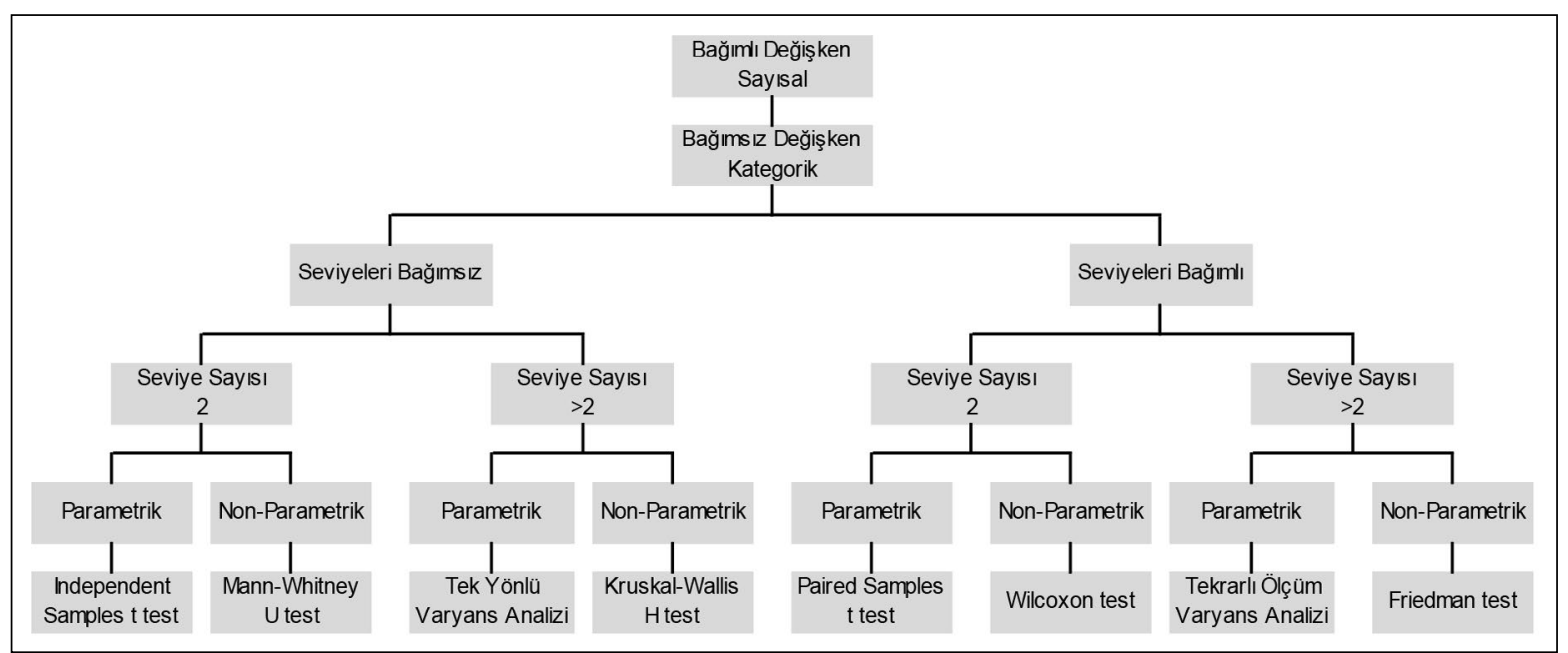

Şekil 1. Bağımlı değişken sayısal, bağımsız değişken kategorik iken uygun test istatistikleri $(1,4,5,9,10)$

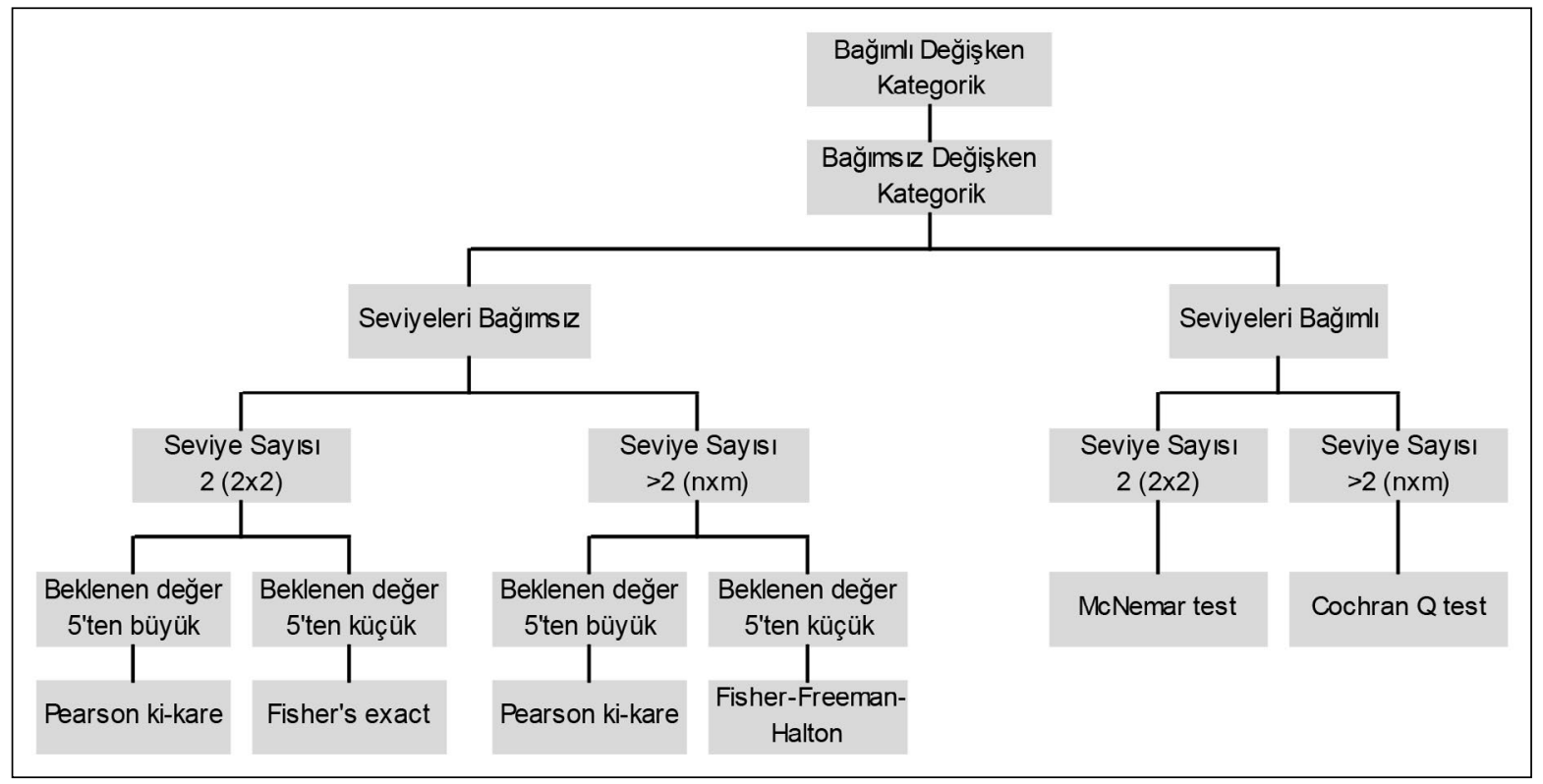

Şekil 2. Bağımlı ve bağımsız değişken kategorik iken uygun test istatistikleri $(1,4,5,9,10)$

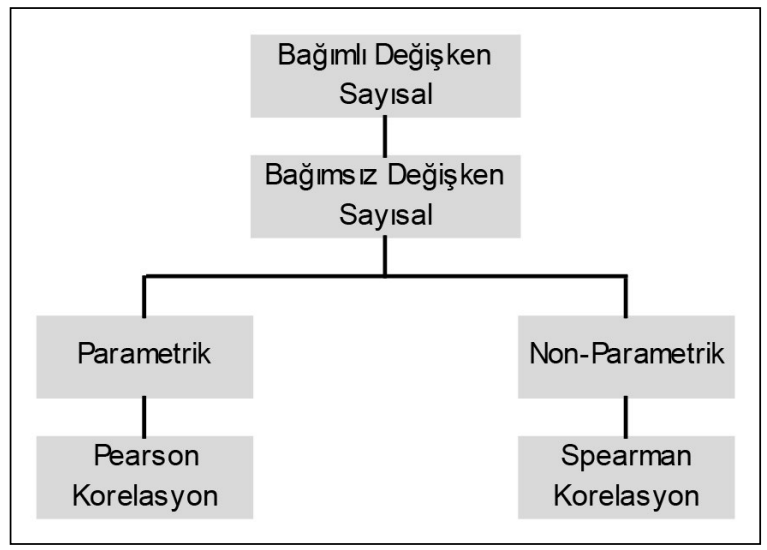

Şekil 3. Bağımlı ve bağımsız değişken sayısal iken uygun test istatistikleri $(1,4,5,9,10)$
PHP çok sayıda platform ve veri tabanıla uyumlu ve güvenli bir şekilde çalışabilen, açık kod mantığı ile gelişmeye sürekli devam eden web tabanlı bir programlama dilidir. Önerilen yapı Linux üzerinde, Apache Server ve mySQL veri tabanı ile kullanılmasıdır (1114). Söz dizim esnekliği ve geniş yetenekleri ile HTML sayfalarının içinde veya bağımsız olarak kullanılabilen PHP kodları, sunucu taraflı çalışmakta ve web sayfasında görünmemektedir, kullanıcı ekranına sadece sonuçlar yansitılmaktadır $(11,12,14,15)$.

JavaScript, yine çok sayıda platform ile uyumlu çalışabilen, nesne tabanlı küçük ve sade bir programlama dilidir. İstemci taraflı çalıştığından kodları kullanı- 
c1 ekranına yansıtılan ve web sayfasında görüntülenen JavaScript ile HTML kodları değiştirilerek daha dinamik uygulamalar ve web sayfaları hazırlanabilmekte, web sayfası bir kez yüklendikten sonra sunucuya bağlı olunmasa da işlemler anlık olarak yapılabilmektedir (15-19).

\section{Karar Ağacı}

$\mathrm{Bu}$ çalışmada, araştırmacıların tek değişkenli basit veya çoklu modellerden hangisini kullanması gerektiğine ve verilerinin istatistiksel analizi için hangi testin daha uygun olduğuna dair bilgi vererek karar verebilmesini sağlayan bir karar ağacı oluşturulmuştur. Oluşturulan bu karar ağacı, tüm web tarayıcılar aracılığıyla görüntülenebilmekte ve kullanıcılara yöneltilen sorulara verilen cevaplara göre çalışmaktadır. Açılır pencereler aracılığıyla, araştırmacıya yöneltilen sorulara yönelik açıklamalar ve örnekler, testlerle ilgili teknik bilgiler ve varsa ön şartlarının neler olduğu ve nasıl test edileceği konularında da açıklamalar içermektedir.

Kullanıcıya sorulan sorular başlangıçta modeldeki bağımlı ve bağımsız değişken sayıları (tek değişkenli modellere yönelik bir karar ağacı olduğundan bağımlı değişken sayısı bir olarak sınırlandırılmıştır) ve tipleri (sayısal veya kategorik) olup daha sonraki sorular, ilk iki aşamadaki cevaplara göre değişkenlik göstermektedir. Tek değişkenli basit (modelde bir bağımlı ve bir bağımsız değiş̧ken olan) modellerde değişkenlerin tipine göre dört farklı durum, çoklu (modelde bir bağımlı ve birden fazla bağımsız değişken olan) modellerde ise altı farklı durum ortaya çıkmakta ve her bir durum için farklı sorularla devam edilerek uygun test istatistiği önerilmektedir. Örneğin her iki değişken de sayısal tipteyken sadece normal dağılıma ilişkin varsayımı kontrol etmek yeterliyken, bağımlı değişken sayısal ve bağımsız değişken kategorik olduğunda, normal dağılım ve varyans homojenliği varsayımlarının kontrol edilmesi gerekmekte, ayrıca bağımsız değişkenin seviye sayısı ve seviyelerin bağımlı olup olmadığı da test seçimini etkilemektedir.

\section{BULGULAR}

$\mathrm{Bu}$ çalışmada oluşturulan karar ağacı, İnternet bağlantısı olan her cihazdan, tüm platformlar ve $J a$ vaScript desteği olan tüm web tarayıcılar aracılı̆̆ıyla ulaşılabilmekte olup sade ve açı anlatımlar sayesinde kolaylıkla kullanılabilmektedir (Şekil 4). Anlaşılmayı kolaylaştırmak için, açıklama ya da örneklendirme gereken yerlerde, açılır pencereler ile kullanıcı desteklenmektedir. Örneğin karar ağacının en başında imlecin "Bağımlı Değişken" kelimesinin üzerine getirilmesi durumunda, "Etkenlerden olumlu ya da olumsuz şekilde etkilendiği düşünülen ve modelde sonuç olarak dikkate alınan değişkendir. Örneğin; diyet tipinin kilo kaybına etkisi." şeklinde bir açıklama ile bağımlı değişkenin hem tanımı hem de bir modeldeki örneği gösterilmektedir (Şekil 5). Uygun test istatistiğini belirlemek için kullanıcıya sorulan sorular, genelden özele doğru hiyerarşik bir şekilde sıralanmakta ve her soruya verilen cevaba göre sadece gerekli olan sorular açılarak hem araştırmacının kendini karmaşık bir yapının içinde bulması engellenmekte hem de bilgi eksikliği ya da yanlış yönlendirmeden kaynaklanan hata yapma olasılı̆̆ı azaltılmaktadır. Ayrıca her aşamada bir önceki sorular ve cevaplar pasif hale getirilerek olası bir yanlış cevap verilmesi de engellenmekte ve en kısa yoldan sonuca gidilmektedir. Cevaptan önceki son sorular ve cevaplar ise aktif halde birakılarak alternatif olabilecek testler arasında (örneğin parametrik olmayan alternatife geçiş vb.) hızlı geçiş sağlanmaktadır (Şekil 6). Test istatistiği belirlendikten sonra aşamalı olarak tüm soruların ekranda toplu halde görülmesi sayesinde bir bütün olarak o teste giden yol haritası da sağlanmış olmaktadır (Şekil 7).

$\mathrm{Bu}$ çalışma kapsamında geliştirilen web tabanlı kılavuza "www.masungur.com/webstat.php" web sayfasında yer alan "istatistik analiz ve hesaplama araçları" yoluyla ya da doğrudan "http://www.masungur. com/test_sec.php” adresine giderek erişilebilmektedir. Ayrıca formun altında, araştırmacıların herhangi bir sorunla karşılaşmaları ya da farklı bir soruları olması durumunda e-posta göndermelerine olanak veren bir bağlantı da bulunmaktadır.

\section{TARTIŞMA ve SONUÇ}

Bir araştırmaya ait verilerin istatistiksel analizi sırasında uygun olmayan bir yöntem kullanılması zaman ve emek kaybıyla sonuçlanacaktır. Test seçiminde yapılacak hata, elde edilecek sonuçların tamamen yanlış 


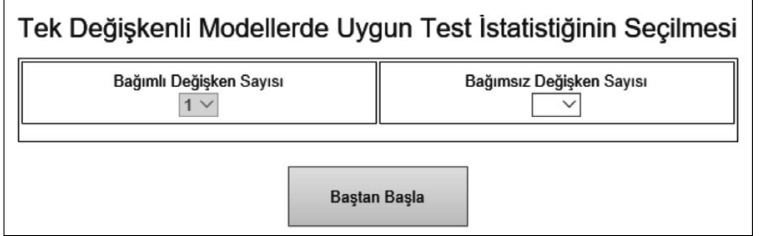

Şekil 4. Karar ağacı başlangıç ekranı

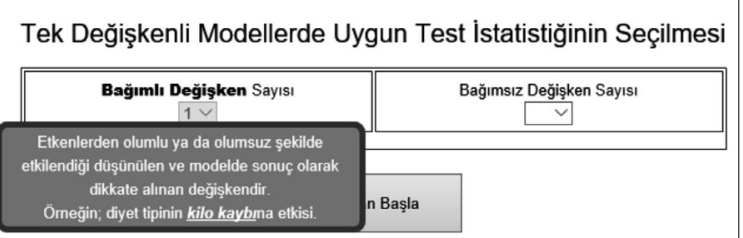

Şekil 5. Açlır pencere ile bilgilendirme örneği

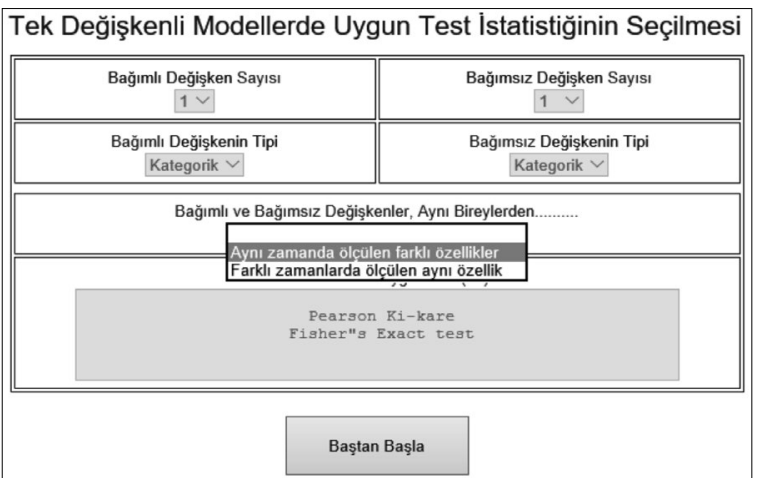

Şekil 6. Son aşamada alternatif testler arasında hızlı geçiş örneği

\begin{tabular}{|c|c|}
\hline Tek Değişkenli Modellerc & Test Istatistiğinin Seçil \\
\hline 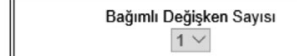 & $\begin{array}{c}\text { Bağımsız Değişsen Sayısı } \\
\begin{array}{|l}1 \vee\end{array}\end{array}$ \\
\hline $\begin{array}{l}\text { Bağımlı Değiskenin Tipi } \\
\qquad \begin{array}{l}\text { Sayısal } \vee \\
\end{array}\end{array}$ & $\begin{array}{l}\text { Bağımsız Değiskenin Tipi } \\
\text { Kategorik } \vee\end{array}$ \\
\hline Bağıılı Değişken Normal Dağıın & mojenliği varsayımlarııı sağlyor mu? \\
\hline $\begin{array}{l}\text { Bağimsız Deḡiskenin Seviyelen } \\
\text { Bağımsı } ~\end{array}$ & 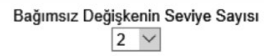 \\
\hline Kullar & Test(ler) \\
\hline Indep & es $t$ test \\
\hline & \\
\hline
\end{tabular}

Şekil 7. Sonuçlanmış bir test seçim ekranı

ya da yanlı olmasına sebep olacaktır. Araştırmacıların genel eğilimi, hangi testin uygun olduğundan ziyade testin nasıl yapıldığını öğrenmektir. Oysa doğru testin seçilmesi, en az testin doğru yapılması kadar -belki de daha da- önemlidir.

$\mathrm{Bu}$ çalışmada, araştırmacıların temel istatistiksel değerlendirmeleri kendi başlarına yapmak istemeleri durumunda çalışmalarının amacına ve verilerin tipine uygun test istatistiğini seçmelerine yardımcı olacak, kolay ulaşılabilir ve kullanılabilir, ayrıca bir uzmandan danışmanlık hizmeti almanın ne kadar önemli olduğu konusunda da farkındalık sağlayacak web tabanlı bir kılavuz geliştirilmiştir.

Uygun istatistiksel test seçimi konusunda, değişken tipi, sayısı ya da çalışmanın amacı gibi soruları farklı sırada dikkate alarak ortaya çıkmış, farklı sınıflandırma şekilleri içeren çok sayıda karar ağacı ve test seçim algoritması vardır (4, 5, 7-10). Ancak bu karar ağaçlarının kullanımı özellikle istatistik uzmanı olmayan kişiler açısından yine de zor ve karmaşı olabilir (6). Böyle bir test seçim kılavuzunda amaç tüm karar ağacını gösterip araştırmacının kafasını karıştırmak değil, karışıklığı azaltmak ve uygun testin seçilmesi olasılığını artırmak olduğundan, bu çalışmada oluşturulan kılavuzda tüm soruları aynı anda göstermek yerine aşamalı olarak her sorunun cevabına göre sıradaki soru alternatifleri belirlenmekte ve kullanıcıya sadece ilgili sorular sorulmaktadır. Böylece hem araştırmacının test seçimi sırasında kendini daha zor bir yol haritasında bulması engellenmekte hem de bilgi eksikliği ya da yanlış yönlendirme nedeniyle doğru yoldan sapma olasılı̆̆ azalmaktadır. Yine özellikle istatistik uzmanı olmayan araştırmacılar açısından, uygun teste karar vermek için önceki sorulara verilen cevaplar pasif hale getirilerek hem önceki cevapların değişmesinden kaynaklanabilecek ani yöntem farklılaşmaları ve olası yanlışlıklar engellenmekte, hem de cevabın hala ekranda görülmesiyle bir bütün olarak o teste giden yol haritası da sağlanmış olmaktadır. Uygun test istatistiği belirlendiğinde ise varsayımların sağlanması, seviyelerin bağımlı ya da bağımsız olması veya seviye sayısı gibi sadece son kararı etkileyecek son aşamadaki sorular ve cevaplar aktif halde birakılarak alternatif olabilecek testler arasında hızlı geçiş sağlanmaktadır. Araştırmacı yanlış giden bir şey olduğunu düşünecek olursa istediği zaman kılavuzu kullanmaya baştan başlayabilmektedir.

Modeldeki bağımlı değişkenin sadece bir tane olduğu modeller tek değişkenli modeller olup bağımsız değişken sayısı da bir olduğunda basit tek değişkenli modeller, bağımsız değişken sayısı birden fazla olduğunda ise çoklu tekli değişkenli modeller söz konusudur. Modeldeki bağımlı değişken sayısının birden fazla 
olması durumunda ise çok değişkenli modeller ortaya çıkmaktadır (1, 20-22). Basit tek değişkenli modelden çoklu tek değişkenli modele geçildiğinde bile verilerin istatistiksel analizinin daha karmaşı modellerle yapılması gerekmektedir. Çok değişkenli modeller söz konusu olduğunda ise kullanılacak istatistiksel analiz teknikleri çok daha karmaşık ve mutlaka uzman düzeyinde destek alınması gereken ileri yöntemlerdir. Bu nedenle bu çalışmada, basit ve çoklu tek değişkenli modellere ilişkin bir kılavuz hazırlanmış olup, çok değişkenli analizlerde uzman düzeyinde istatistiksel bilgi gerektiği ve gerek model kurulumunun gerekse analizin çok dikkatlice yapılması gerektiği için çok değişkenli modellerden bahsedilmemiştir. Çoklu tek değişkenli modeller için ise kullanıcıya uygun test istatistiğinin seçimi konusunda yardım sağlanmakla birlikte kullanıcı mutlaka bir uzman desteği alması gerektiği yönünde sıklıkla uyarılmıştır. Dolayısıyla, uygun test istatistiğini seçme konusunda destek sağlanırken, daha karmaşık yöntemlerin varlığı konusunda da farkındalık sağlanmış ve prensipte uzman yardımı almanın önemi vurgulanmış olmaktadır.

Sonuç olarak, veri içeren bir çalışmanın bulgularını ortaya koyarken kullanılan istatistiksel yöntem, araştırmanın sonuçlarını doğrudan etkileyebileceği için uygun test istatistiğinin seçilmesi oldukça önemlidir. Bu çalışmada, uygun istatistiksel test seçiminde hangi konulara dikkat edilmesi gerektiği ve bu doğrultuda ortaya çıkabilecek test istatistikleri konusunda bilgilendirme yapılmış, tek değişkenli basit ve çoklu modellerde uygun test istatistiğinin seçilmesi konusunda web tabanlı bir kılavuz geliştirilmiştir.

\section{KAYNAKLAR}

1. Ankaralı H, Cangür Ş, Sungur MA. Formülsüz Biyoistatistik. İstanbul: BETİM; 2015.

2. Jaykaran D. How to select appropriate statistical test. J Pharm Negative Results. 2010;1(2):61-3.

3. Nayak BK, Hazra A. How to choose the right statistical test? Indian J Ophthalmol. 2011;59(2):85-6.

4. Johnson LR, Karunakaran UD. How to choose the appropriate statistical test using the free program statistics Open For All (SOFA). Annals of Community Health. 2014;2(2):54-62.

5. Marusteri M, Bacarea V. Comparing groups for statistical differences: how to choose the right statistical test? Biochemia Medica. 2010;20(1):15-32.
6. Suner A, Karakülah G, Koşaner Ö, Dicle O. StatXFinder: A web-based self-directed tool that provides appropriate statistical test selection for biomedical researchers in their scientific studies. SpringerPlus. 2015;4:633.

7. Saltikov JB, Whittaker WJ. Selecting the most appropriate inferential statistical test for your quantitative research study. J Clin Nurs. 2013;23:1520-31.

8. Watt JH, van den Berg SA. Selecting Statistical Tests. Research Methods for Communication Science, 2. ed. Albany: Rensselaer Polytechnic Institute; 2002:302-29.

9. Parab S, Bhalerao S. Choosing statistical test. Int J Ayurveda Res. 2010;1(3):187-91.

10. Andrews FM, Klem L, Davidson TN, O'Malley PM, Rodgers WL. A Guide for Selecting Statistical Techniques for Analyzing Social Science Data, 2. ed. ABD: University of Michigan; 1981.

11. Naramore E, Gerner J, Scouarnec YL, Stolz J, Glass MK. Beginning PHP5, Apache, and MySQL web development. Indianapolis: Wiley; 2005:1-660.

12. Yank K. Introducing PHP. Build Your Own Database Driven Web Site Using PHP \& MySQL, 4th ed. Victoria, AU: SitePoint Pty Ltd; 2009:73-113.

13. Rochkind M. Platforms and Tools. Expert PHP and MySQL. New York: Apress; 2013:45-81.

14. Suehring S, Converse T, ParkJ. PHP 6 and MySQL 6 Bible. Indianapolis: Wiley; 2009:1-793.

15. Alan MA, Gülmez M. The comparison of some database administration languages on the Internet. C.Ü. İktisadi ve İdari Bilimler Derg. 2001;2(2):61-5.

16. Stefanov S. JavaScript for PHP Developers. Sebastopol: O’Reilly; 2013:1-136.

17. Zakas NC. Professional JavaScript for Web Developers, 3. ed. Indianapolis: Wiley; 2012:1-856.

18. Morrison M. The Interactive Web: Reacting to the Virtual World. Head First JavaScript. Sebastopol: O'Reilly; 2008:1-31.

19. McFarland DS. Writing Your First JavaScript Program. JavaScript \& jQuery, The Missing Manual, 2. ed. Sebastopol: O'Reilly; 2012:21-40.

20. Huberty CJ, Morris JD. Multivariate analysis versus multiple univariate analyses. Psychol Bull. 1989;105(2):3028.

21. Day S. Dictionary for Clinical Trials, 2. ed. Wiltshire: Wiley; 2007:1-249.

22. Daniel WW, Cross CL. Biostatistics: A Foundation for Analysis in the Health Sciences, 10. ed. ABD: Wiley; 2014:1-960. 